\title{
A INCORPORAÇÃO DE PRINCÍPIOS DE SEGURANÇA ALIMENTAR E NUTRICIONAL AO PROGRAMA NACIONAL DE ALIMENTAÇÃO ESCOLAR: TRAJETÓRIA E PERSPECTIVAS
}

Vanessa Schottz ${ }^{1}$

\begin{abstract}
RESUMO
O presente artigo aborda os esforços recentes de incorporação de princípios de Segurança Alimentar e Nutricionais (SAN) ao Programa Nacional de Alimentação Escolar e que resultaram na obrigatoriedade de aquisição de um percentual mínimo de $30 \%$ de produtos da agricultura familiar. Busca-se, a partir dos quadros analíticos das coalizões de causa (ACF) e da Instrumentação da Ação Pública (IAP), refletir acerca dos fatores que possibilitaram que organizações sociais pudessem influenciar, não apenas a aprovação da lei 11.947/2009, mas, também, o processo de regulamentação dos mecanismos de compra da agricultura familiar. Foram realizadas entrevistas com informanteschave, observação participante e análise documental. A institucionalização da compra esteve fortemente associada à atuação de coalizões de atores articulados em torno da ideia de SAN e do fortalecimento da agricultura familiar em um ambiente político e institucional permeável às demandas da sociedade civil e caracterizado pela centralidade da política de SAN na agenda pública. Com as profundas mudanças ocorridas no contexto pós-impeachment, não se mantiveram as condições que favoreceram as inovações sociais produzidas no âmbito do programa, o que poderá comprometer o processo de compra de alimentos da agricultura familiar.

Palavras-chave: Programa Nacional de Alimentação Escolar, Agricultura Familiar, Segurança Alimentar e Nutricional.

\section{THE INCORPORATION OF PRINCIPLES FROM FOOD AND NUTRITION SECURITY TO THE NATIONAL SCHOOL FEEDING PROGRAM: TRAJECTORY AND PERSPECTIVES}

\begin{abstract}
The present article addresses the recent efforts on the incorporation of principles from Food and Nutrition Security (FNS) to the National School Feeding Program, which resulted in a mandatory purchase of a minimum of $30 \%$ of products from Family Farming. From the analytical Advocacy Coalition Framework (ACF) and the Instrumentalization of Public Action (IAP), it aims to reflect about the factors that allowed social organizations to influence not only the approval of Law $11.947 / 2009$ but also the process of regulation of family farming's purchase mechanisms. Interviews with key-informants, participant observation and documental analysis were conducted as part of the methodology. The institucionalization of such purchase was strongly related to the action of coalitions of actors that were articulated around the idea of FNS and the strengthening of Family Farming within a political and institutional environment that was permeable to the civil society's demands and characterized by the centrality of the FNS policy within the public agenda. After the deep changes that have occurred within the post-impeachment context, the conditions that favoured the social innovations that were produced within the program have not been kept, that may compromise the food purchasing process from family farming.
\end{abstract}

Keywords: National School Feeding Program, Family Farming, Food and Nutrition Security

\footnotetext{
${ }^{1}$ Nutricionista, Doutora em Ciência Sociais em Desenvolvimento, Agricultura e Sociedade pelo CPDA/UFRRJ. Professora do curso de Nutrição da UFRJ Campus Macaé. Professora do Programa de Pós Graduação em Segurança Alimentar e Nutricional da UNIRIO (PPGSAN). Pesquisadora associada ao Centro de Referência em Segurança Alimentar e Nutricional (CERESAN). E-mail: vanessaschottz32@gmail.com
} 


\section{INTRODUÇÃO}

Este artigo busca refletir acerca das combinações de fatores capazes de possibilitar a emergência e a continuidade dos processos de inovação social no âmbito das políticas públicas, considerando, sobretudo, trajetórias de transformação política e institucional que tentam se contrapor às formas dominantes de definição e regulação dos problemas públicos, encontrando suporte na atuação de movimentos sociais e de redes de organizações da sociedade civil.

Moulaet et al $(2005)^{2}$, em um esforço por construir um quadro conceitual capaz de possibilitar uma análise transversal de experiências alternativas de governança em comunidades urbanas desenvolvidas no contexto europeu, propõem uma definição operacional do conceito de inovação social que nos parece adequada ao caso aqui analisado. Para estes autores, a inovação social envolve mudanças capazes de promover a inclusão de grupos e indivíduos socialmente excluídos, implicando, necessariamente um posicionamento ético em favor da justiça social.

Nessa perspectiva, os referidos autores consideram que a inovação social apresenta um conjunto integrado de características. Define-se, inicialmente, por sua natureza contextual e pela dependência em relação a uma determinada trajetória institucional, envolvendo transformações em agendas, agenciamentos e instituições, que caminham na direção de uma maior inclusão de grupos ou indivíduos em distintas esferas sociais e em diferentes escalas espaciais. Envolve, acima de tudo, um processo de inovação, com alterações nas relações sociais e nas relações de poder, e uma disputa com forças conservadoras que buscam manter determinadas situações de exclusão (Moulaert et al, 2005).

As dinâmicas de inovação social, analisadas nesse artigo, encontram-se associadas à construção social de quadros conceituais e de estratégias através das quais os atores sociais procuram reinventar objetos, imaginários e projetos hegemônicos, ampliando ou modificando determinadas agendas e institucionalizando, dentro de suas possibilidades, novos instrumentos de intervenção governamental.

Tomamos, neste caso específico, como foco de reflexão, os encadeamentos que possibilitaram a incorporação de princípios de Segurança Alimentar e Nutricional (SAN) aos instrumentos de implementação do Programa Nacional de Alimentação Escolar (PNAE), com especial atenção ao mecanismo de compra sem licitação de produtos oriundos da agricultura familiar. A incorporação por parte do poder público de propostas construídas ao longo de mais de uma década por uma rede heterogênea de atores, contando com participação de pessoas e organizações com inserção tanto na sociedade civil como em espaços governamentais, materializaram-se, em 2009, na aprovação e na

\footnotetext{
${ }^{2}$ Uma descrição mais aprofundada dos casos que subsidiaram as reflexões destes autores encontra-se disponível em: http://users.skynet.be/frank.moulaert/singocom/index2.html. Acesso em: 12/06/2018.
} 
regulamentação de uma nova lei que reformulou os princípios e diretrizes do PNAE (Lei 11.947/2009). Este novo marco regulatório estabeleceu, em seu artigo 14, a obrigatoriedade da utilização de até 30\% dos recursos financeiros repassados pelo Fundo Nacional de Desenvolvimento da Educação (FNDE) ${ }^{3}$, na compra, sem licitação, de "gêneros alimentícios diretamente da agricultura familiar e do empreendedor familiar rural ou de suas organizações, priorizando-se os assentamentos da reforma agrária, as comunidades tradicionais indígenas e comunidades quilombolas" (Brasil, 2009).

Ao longo desse processo, a coalizão de causa ${ }^{4}$ que se estruturou, historicamente, em torno da SAN, articulada a uma ampla rede de atores que atuavam, desde os anos 1990, em favor da agricultura familiar e de seu reconhecimento pelas políticas públicas como uma categoria específica, conseguiu não apenas influenciar a formulação e aprovação da nova Lei do PNAE, como participar de seu processo de regulamentação. A incorporação dos princípios defendidos pela coalizão de SAN aos instrumentos de políticas públicas envolveu um movimento complexo e multidimensional de inovação social que não pode ser apreendido, plenamente, nem por uma abordagem centrada de maneira exclusiva no Estado e na racionalidade das instituições governamentais, e nem por uma análise voltada, unicamente, para a capacidade de agência das redes e organizações sociais.

Concordamos, aqui, com Lascoumes e Le Galès (2012) quando sugerem que as dinâmicas relacionadas à construção e à institucionalização das políticas públicas podem ser percebidas como um processo interativo, envolvendo: os atores sociais; os quadros cognitivos e normativos que dão sentido às suas ações; as instituições (normas, regras e rotinas) em que estão enquadradas as ações públicas; os processos e resultados produzidos ao longo do tempo e que alimentam recursivamente estas interações.

Partimos do pressuposto de que as dinâmicas de ação coletiva que levaram à construção deste mecanismo foram amplamente favorecidas pela existência de um ambiente de maior permeabilidade do Estado às demandas das organizações da sociedade civil que caracterizou os governos de coalizão liderados pelo Partido dos Trabalhadores $(2003-2016)^{5}$, e pela centralidade adquirida pelas políticas de combate à fome, à pobreza e às desigualdades sociais na agenda pública desse período.

Considerando as drásticas mudanças ocorridas no cenário político desde o impeachment da presidenta Dilma Rousseff, com enormes repercussões sobre o grau de permeabilidade do sistema

\footnotetext{
${ }^{3}$ Autarquia federal criada em 1968 e vinculada ao Ministério da Educação. Responsável pela gestão dos recursos oriundos do orçamento da União destinados à alimentação escolar.

${ }^{4}$ Utilizamos, aqui, o quadro analítico da Coalizão de Causa (ACF) elaborado por Sabatier e Jenkins Smith (1993), Sabatier e Weible (2007), Weible, Sabatier e McQueen (2009), entre outros. A coalizão de causa pode ser entendida como um conjunto de atores sociais (governamentais e não governamentais) que compartilham crenças e valores que interagem em um determinado subsistema de políticas, buscando influenciar os processos decisórios.

${ }^{5}$ Primeiro governo Lula (2003-2006), segundo governo Lula (2007-2010), primeiro mandato Dilma Rousseff (20112014), segundo mandato Dilma Rousseff, interrompido pelo impeachment (2015-2016).
} 
político e das instituições do Estado às demandas da sociedade civil e à participação das organizações sociais nos processos decisórios, interrogamos-nos, em meio a um ambiente marcado pelo desmonte acentuado do Sistema Nacional de SAN e das políticas para a agricultura familiar, acerca da continuidade deste processo de inovação social.

Esta pesquisa foi resultado de um trabalho continuado de investigação, desenvolvido ao longo de três anos, e que deu origem à tese de doutorado intitulada Programa Nacional de Alimentação Escolar (PNAE): controvérsias sobre os instrumentos de compra de alimentos produzidos pela Agricultura Familiar. A pesquisa envolveu a utilização de diferentes técnicas, incluindo observação participante, realizada no âmbito do Comitê Gestor e Grupo do Consultivo do PNAE (espaços formais voltados para a regulamentação do artigo da Lei 11.947 que tratava da compra da agricultura familiar), análise documental e a realização de entrevistas em profundidade com informantes-chave (governamentais e não governamentais). As reflexões que subsidiam as avaliações relativas à consolidação do mecanismo de compra da agricultura familiar no cenário pós-impeachment envolveram o levantamento de dados secundários e exercícios pontuais de observação participante, desenvolvidos em um período posterior à apresentação da tese.

O presente artigo encontra-se estruturado em três diferentes seções. Resgatamos, inicialmente, a trajetória de incorporação da compra da agricultura familiar na história institucional do PNAE, chamando atenção para o fato de que a necessidade de priorizar alimentos básicos, característicos da cultura brasileira, introduzindo produtos cultivados por pequenos agricultores ${ }^{6}$, já estava presente no debate público em torno do programa desde os anos 1970. Abordamos, na sequência, os processos que possibilitaram a incorporação de princípios de SAN na Lei do PNAE e nos normativos que regulamentaram, no âmbito do programa, a compra da agricultura familiar. Tendo como substrato as análises apresentadas nas seções anteriores, buscamos, por fim, avaliar as perspectivas de continuidade da compra da agricultura familiar, como um processo de inovação social, no período pós-impeachment.

\section{A COMPRA DE ALIMENTOS ORIUNDOS DA AGRICULTURA FAMILIAR NA TRAJETÓRIA INSTITUCIONAL DO PNAE}

O PNAE é considerado, atualmente, como o mais antigo programa de alimentação e nutrição no Brasil. Sua trajetória remonta aos anos 1950, com a institucionalização, em 1954, pelo Ministério

\footnotetext{
${ }^{6}$ Neste texto, a categoria 'agricultura familiar' foi considerada como uma construção política e social que emerge, historicamente, através da agência de diferentes atores (movimentos sociais, gestores públicos, acadêmicos), consolidando-se, progressivamente, como uma referência política e institucional no campo das políticas públicas e abarcando diferentes perfis de produtores e identidades sociais. Em períodos anteriores, termos como 'pequeno agricultor', 'camponês', entre outros, foram utilizados como forma de identificar a produção agrícola de base familiar em suas distintas formas. Autores como Picolloto (2011) e Grisa; Schneider (2014) abordam de forma mais aprofundada essa questão referente ao processo histórico de construção da categoria 'agricultura familiar'.
} 
da Saúde, do Programa Nacional de Merenda Escolar e, posteriormente, em 1955, da Campanha da Merenda Escolar pelo Ministério da Educação. Tratava-se de uma campanha de abrangência nacional que tinha como objetivo a distribuição de leite em pó enriquecido com farinhas de leguminosas e cereais, fabricadas por pequenas indústrias nacionais.

Ao longo de sua trajetória, o PNAE passou por diversas transformações, tanto no que diz respeito às ideias e aos valores que orientaram a estruturação do programa, como no que tange ao seu desenho de implementação. Em linhas gerais, a história institucional desta política pública pode ser dividida em quatro momentos distintos: i) 1954 a 1971 - distribuição de alimentos sob a forma de Campanha Nacional com recursos advindo da ajuda alimentar internacional; ii) 1972 a 1993 conformação de um programa com recursos nacionais e gestão centralizada no governo federal; iii) 1994 a 2002 - descentralização do programa com transferência de recursos e da gestão para os estados e municípios; iv) a partir de 2003 - conformação do PNAE como ação estratégica de promoção da SAN (Coimbra, 1981; Turpin, 2008; Carvalho, 2009; Peixinho, 2011).

A criação do PNAE na década de 1950 esteve fortemente vinculada às ações desenvolvidas pelo Estado brasileiro nas áreas de saúde e de nutrição e às parcerias estabelecidas com órgãos de assistência e cooperação internacional, incluindo o USAID (Agência Norte-Americana para o Desenvolvimento Internacional), a Organização das Nações Unidas para a Alimentação e Agricultura (FAO), entre outros. A distribuição de leite em pó, farinhas industrializadas com adição de nutrientes e, posteriormente, já na década de 1960, refeições compostas por preparações prontas e semiprontas (almoço escolar), marcou a oferta de alimentos destinados à população escolar nesse período. A partir de meados da década de 1960, em caráter complementar, o Estado passou a oferecer, também, verduras e legumes distribuídos pelos governos estaduais.

Na década de 1970, sob a égide dos Planos Nacionais de Desenvolvimento implantados pelos governos militares, a, então designada, Campanha Nacional de Alimentação Escolar (CNAE) passou a se constituir como uma política pública, com recursos nacionais e gestão centralizada no governo federal. Nesse novo ambiente, é possível identificar uma tentativa de incorporação da alimentação escolar à agenda desenvolvimentista. Assume-se, formalmente, como uma prioridade, a utilização de alimentos básicos e próprios da cultura alimentar brasileira, como arroz e feijão, e a compra de produtos cultivados por pequenos produtores, em lugar dos alimentos formulados adquiridos das grandes empresas. Esta nova agenda, planejada durante o chamado 'milagre econômico', mas implementada já em plena crise fiscal do Estado, encontrou como obstáculos para sua execução a baixa disponibilidade de recursos financeiros e a fragilidade institucional dos órgãos responsáveis pela sua operacionalização, particularmente do Instituto Nacional de Alimentação e Nutrição (INAN).

A aquisição de alimentos fornecidos por pequenos produtores de base familiar, embora já estivesse conceitualmente presente nas diretrizes de implementação do programa, não conseguia se 
traduzir em dispositivos operacionais capazes de viabilizar a construção de elos mais efetivos entre a produção familiar e a alimentação escolar. Manteve-se, na prática, a estruturação de cardápios constituídos, principalmente, por alimentos 'formulados', em pó, utilizados na preparação de sopas e mingaus com a adição de água. A qualidade nutricional destes alimentos foi, no entanto, duramente criticada por estudiosos da área da nutrição preocupados com o agravamento, no país, do quadro de desnutrição infantil. Cabe observar, ao mesmo tempo, que os critérios estabelecidos pelo INAN para a preparação desses 'formulados', e que se somavam aos desafios envolvidos na implantação de uma logística centralizada de distribuição dos gêneros alimentícios destinados à alimentação escolar, só conseguiam ser enfrentados por empresas de grande porte e que conseguiam importar algumas matérias primas fornecidas por empresas multinacionais. (Turpin, 2008; Carvalho, 2009).

A partir do final da década de 1970, em um cenário marcado pela crise econômica e pelo visível desgaste dos governos militares, um novo ciclo de transformações viria a afetar a arquitetura institucional do PNAE. Em 1979, a CNAE passou a se chamar Programa Nacional de Alimentação Escolar (PNAE). Com a criação, em 1983, da Fundação de Assistência ao Estudante (FAE), foi adotado um formato misto de aquisição, que buscava assegurar, simultaneamente, a continuidade da compra de alimentos 'formulados' pela FAE, introduzindo, ao mesmo tempo, a compra descentralizada de alimentos básicos em parceria com as Secretarias Estaduais de Educação (SEEs). Registra-se, ainda, em meados da década de 1980, uma primeira tentativa de municipalização do programa, mas que não conseguiu avançar em função de irregularidades nas prestações de contas por parte dos municípios e descontinuidades no repasse de recursos (Turpin, 2008).

A nova Constituição Federal, aprovada em 1988, teve como uma de suas marcas a transferência de recursos e de competências atribuídas ao governo federal para os estados e municípios, processo que afetou o desenho institucional de diferentes políticas públicas, entre elas o PNAE. O direito dos alunos do ensino fundamental à alimentação escolar, embora reconhecido pela nova carta constitucional, não encontrou amparo efetivo no receituário neoliberal adotado pelo Governo Collor a partir de 1990. Nesse mesmo período, diante das denúncias do Movimento pela Ética na Política (MEP) em relação à corrupção e ao desmonte das políticas de combate à fome pelo governo eleito, foi aberta, no Congresso Nacional, uma 'Comissão Parlamentar de Inquérito Destinada a Examinar as Causas da Fome e a Iminente Ameaça à Segurança Alimentar no País (CPI da Fome)'.

O PNAE também foi auditado pelo Tribunal de Contas da União (TCU), que identificou diversos problemas e irregularidades na implementação desta política pública, incluindo: desvios e fraudes na distribuição de alimentos; usos eleitorais do programa; deterioração dos produtos estocados; cartelização envolvendo setores da indústria de alimentos - com destaque para os responsáveis pelo fornecimento de 'formulados' e leite em pó - e, por fim, irregularidades 
administrativas na aquisição de alimentos. A compra e distribuição de produtos básicos, executada pela Companhia Nacional de Abastecimento (CONAB) foi, igualmente, alvo de críticas, avaliandose que, nessas operações, os recursos destinados ao programa acabavam, na visão do TCU, sendo absorvidos pelos cofres da CONAB, comprometendo os objetivos finalísticos do programa (Brasil, 1993b).

Verifica-se, nos anos 1990, a exemplo do que ocorreu com outras políticas, um movimento de descentralização do PNAE, que passa a ser operado mediante o repasse dos recursos provenientes do Orçamento Geral da União (OGU) aos governos estaduais e municipais através de convênios. Os entes federados envolvidos na execução do programa passaram a ser responsáveis pelo planejamento e execução dos cardápios, que deveriam ser elaborados por um/a nutricionista, buscando respeitar os hábitos alimentares e a vocação agrícola regional, e priorizar a aquisição de produtos de cada região, preferencialmente alimentos in natura. Soma-se a isso, a estruturação, em caráter obrigatório, dos Conselhos de Alimentação Escolar (CAEs), compostos por representantes dos professores, dos pais e alunos, de organizações sociais e do poder público, tendo por objetivo acompanhar as ações do programa e fiscalizar sua execução. A ênfase atribuída à origem regional dos alimentos não se traduzia, no entanto, na aquisição de alimentos produzidos por pequenos agricultores. Chama atenção, além disso, o escasso envolvimento das organizações representativas dos trabalhadores no campo ou dos "pequenos produtores" nos debates relacionados à descentralização do PNAE. Além de gestores públicos, participaram, de uma forma mais ativa desse processo, representantes de grupos e entidades do campo da nutrição.

Do ponto de vista prático, a Lei 8.666/1993, responsável pela definição de normas para licitações e contratos estabelecidos pela Administração Pública, apresentava-se como um poderoso obstáculo à participação dos agricultores de base familiar como fornecedores dos alimentos destinados à alimentação escolar. Isso ocorria, em primeiro lugar, em função das dificuldades enfrentadas pelos chamados 'pequenos produtores' ou 'agricultores familiares' no sentido de atender às exigências legais que poderiam viabilizar sua habilitação físcal, jurídica e econômica para atuar no programa; e, em segundo lugar, pela sua dificuldade em competir com os preços oferecidos pelas grandes empresas envolvidas no fornecimento de produtos, em grande escala, para o atendimento a esse mercado.

A partir de 2003, com a vitória de Lula, vinculado ao Partido dos Trabalhadores (PT), nas eleições presidenciais, liderando uma coalizão de forças composta por diferentes partidos, verificase uma maior abertura do sistema político à participação social e às demandas vocalizadas pelos movimentos sociais do campo, incluindo aí as organizações da agricultura familiar. Soma-se a isso o fato de que o combate à fome e a promoção da SAN alcançaram especial destaque na agenda política do primeiro governo Lula com o lançamento do Programa Fome Zero, cujas diretrizes já haviam sido 
publicizadas em 2001 com a publicação do documento Projeto Fome Zero-uma proposta de política de segurança alimentar para o Brasil.

Verifica-se neste contexto uma convergência entre: (i) os diferentes atores ligados à agricultura familiar; (ii) a coalizão de causa que, desde a década de 1990, vinha se articulando em torno do combate à fome e da construção de referências compartilhadas de incorporação da SAN no âmbito das políticas públicas; (iii) gestores públicos e dirigentes políticos empenhados em dar concretude ao programa de governo que havia sido defendido nas eleições. Argumenta-se, aqui, que o entrelaçamento entre esses diferentes interesses, que passam a convergir na implantação de uma nova agenda de políticas públicas, abriu caminhos para a institucionalização de mecanismos de compra de produtos da agricultura familiar no atendimento ao PNAE, com dispensa do procedimento licitatório.

\section{A INCORPORAÇÃO DOS PRINCÍPIOS DE SAN AOS INSTRUMENTOS DE POLÍTICAS PÚBLICAS: DA LEI DO PNAE À OPERACIONALIZAÇÃO DA COMPRA DA AGRICULTURA FAMILIAR}

A emergência na trajetória brasileira de um conjunto articulado de atores que passa a incidir de forma organizada no espaço público, denunciando a situação de insegurança alimentar e nutricional existente no país - interpretada como uma violação de direitos -, elaborando estudos e propostas destinadas à superação deste quadro de injustiça social, tem sido abordada por diferentes autores, tais como Zimmerman, (2011) e Leão; Maluf (2012). Não cabe aqui retomar esse percurso histórico que remonta às análises formuladas por Josué de Castro sobre as raízes da fome no Brasil (Castro, 1946), passando pela campanha Ação da Cidadania contra a Fome a Miséria e pela Vida, liderada pelo sociólogo Herbert de Souza no início dos anos 1990, a criação do Conselho Nacional de Segurança Alimentar e Nutricional (CONSEA) no governo Itamar Franco, sua posterior extinção no Governo Fernando Henrique Cardoso e recriação no primeiro Governo Lula, em 2003. Parece-nos importante salientar, no entanto, que esta coalizão é composta por um conjunto heterogêneo e cambiante de atores, delineando suas fronteiras em função de diferentes recortes temáticos e conjunturas. Estão presentes nesta articulação os ativistas organizados no Fórum Brasileiro de Soberania e Segurança Alimentar e Nutricional (FBSSAN), associações profissionais ligadas à área de saúde e nutrição, movimentos sociais diversos, organizações vinculadas à agricultura familiar, diferentes tipos de organizações não governamentais, gestores públicos, entre outros segmentos.

Entendemos aqui, no entanto, que a institucionalização do mecanismo de compra da agricultura familiar no âmbito do PNAE envolveu um universo significativamente mais amplo de pessoas e organizações, com destaque para um conjunto inter-relacionado de atores ligados à agricultura familiar e diversos parlamentares, articulados na Frente Parlamentar de SAN. 
No que se refere, especificamente, ao tema da agricultura familiar, diversas análises têm resgatado o processo de emergência desta categoria específica no campo das políticas públicas, a partir da década de 1990, e seu processo de legitimação como segmento responsável pela produção de alimentos destinados ao mercado interno (Picolotto, 2011; Grisa, 2012; Grisa; Schneider, 2014). Conforme observado por Grisa e Schneider (2014), é possível identificar na trajetória brasileira diferentes gerações ou referenciais de políticas públicas voltadas ao fortalecimento da agricultura familiar. Nos termos sugeridos pelos autores, a formulação de mecanismos específicos capazes de viabilizar a compra de alimentos produzidos pela agricultura familiar no âmbito do PNAE inscrevese, justamente, em uma terceira geração de políticas voltadas a este setor e que foi fortemente influenciada por princípios relacionados à SAN e à sustentabilidade ambiental.

A análise da Lei 11.947/2009 aponta, justamente, para uma convergência entre o PNAE com alguns princípios e diretrizes da Política Nacional de Segurança Alimentar e Nutricional (PNSAN), na medida em que os objetivos e as diretrizes estabelecidos para o programa buscaram concretizar a perspectiva da alimentação escolar como direito humano e de seu papel estratégico na promoção da alimentação adequada e saudável dos escolares, e no apoio ao desenvolvimento sustentável, por meio da aquisição de alimentos locais diversificados, produzidos pela agricultura familiar. O PNAE, segundo a lei, tem, como objetivo, contribuir para o desenvolvimento biopsicosocial, aprendizagem, rendimento escolar e a formação de hábitos alimentares saudáveis. Suas diretrizes são: i) inclusão da Educação Alimentar e Nutricional no processo de ensino aprendizagem; ii) oferta de alimentação adequada e saudável; iii) direito humano à alimentação adequada; iv) participação e controle social e; v) apoio ao desenvolvimento local.

Maluf (2009) considera que essas diretrizes, orientadas pelo enfoque intersetorial de SAN, possibilitaram que o PNAE criasse um elo institucional entre a oferta de alimentos saudáveis na escola, o processo de ensino e aprendizagem e a agricultura familiar. Foi em consonância com essas diretrizes que a legislação introduziu algumas inovações no modus operandi do programa, principalmente no que se refere às dinâmicas de aquisições públicas de alimentos (mínimo de 30\% da agricultura familiar via chamada pública) e de elaboração dos cardápios, que devem se pautar não só pelo atendimento das necessidades nutricionais dos escolares, mas incorporar as dimensões da sustentabilidade e do respeito à cultura e aos hábitos alimentares.

A coordenação do PNAE e o Ministério do Desenvolvimento Agrário (MDA) argumentaram, em diversos documentos públicos, que a inserção da produção da agricultura familiar na alimentação escolar fortaleceria o papel estratégico do programa na garantia da SAN, possibilitando novas conexões entre a produção e o consumo. As compras da agricultura contribuiriam também para valorizar e gerar renda para este segmento, reduzir a insegurança alimentar no campo e incentivar a produção diversificada e sustentável de alimentos. 
A triangulação dos dados da pesquisa indica que a combinação de alguns fatores impactou fortemente o subsistema de $\mathrm{SAN}^{7}$ e gerou novas "estruturas de oportunidades de coalizão" (Weible; Sabatier, 2007) que fortaleceram a coalizão de SAN a disputar, no âmbito da agenda de governo, a institucionalização de seu projeto político, que envolvia a reorientação do PNAE e a adoção de mecanismos de compra da agricultura familiar. Para esses autores, as estruturas de oportunidades podem variar conforme o grau de permeabilidade do sistema político à participação de diferentes atores sociais nos processos decisórios.

Nessa perspectiva, a eleição de Lula (PT) para a Presidência da República, em 2002, criou um ambiente favorável à reorientação do PNAE em função: i) da prioridade política conferida ao programa, que passou a compor a agenda de ações estratégicas do Programa Fome Zero, e da nomeação de uma gestora comprometida com o campo da SAN; ii) da adoção de um conjunto de políticas voltadas para a inserção social e produtiva da agricultura familiar, processo este que contribuiu para o fortalecimento desse segmento social e das suas dinâmicas organizativas; iii) da progressiva institucionalização da SAN enquanto política pública e; iv) do fortalecimento de espaços de interlocução entre o Estado e a sociedade civil, com destaque para a recomposição do CONSEA.

O CONSEA exerceu um papel central nesse processo ao promover o diálogo e a interlocução entre diversos atores sociais e diferentes setores de governo, e ao considerar a multiplicidade de olhares e interesses no exercício democrático de reorientação do programa. O grupo de trabalho sobre o PNAE (GT PNAE), instituído pelo CONSEA em 2004 e formado por conselheiros da sociedade civil e pela equipe técnica e coordenação do programa, foi responsável pela elaboração da primeira versão do Projeto de Lei que, após um longo processo de negociação entre diversos órgãos do governo federal e gestores estaduais e municipais de educação, foi encaminhado pela Casa Civil à Câmara dos Deputados.

Outro fator importante foi a atuação articulada das coalizões de SAN e da agricultura familiar para incidir sobre a Lei do PNAE. Destaca-se que o aprendizado desses atores no âmbito institucional e a experiência positiva com o Programa de Aquisição de Alimentos (PAA) conferiram as bases para que fosse incluído na legislação um dispositivo garantindo a destinação de recursos para a compra de alimentos da agricultura familiar, com dispensa de licitação. Visando ampliar o debate e o apoio público ao Projeto de Lei e intensificar a pressão sobre o Congresso Nacional foi constituída uma comissão de mobilização e monitoramento do PNAE, que atuou em parceria com a Frente Parlamentar de SAN, para a indicação de membros para assumir a presidência e a relatoria das comissões, dentre outras ações de incidência política. A comissão era formada pelo FBSSAN,

7 Tomando como base a abordagem da Coalizão de Causa (ACF) (Sabatier e Jenkins-Smith, 1993), a SAN é considerada nesta pesquisa como um subsistema de política, uma vez que se constitui em um problema público em torno do qual se conforma determinados campo de relações produzidos a partir da interação entre diversos atores que buscam incidir sobre essa política pública, orientados por um conjunto de crenças e valores que partilham entre si. 
Articulação Nacional de Agroecologia (ANA), Associação Brasileira de Alimentação e Nutrição (ASBRAN), Fórum Brasileiro de Economia Solidária (FBES), Movimento de Pequenos Agricultores (MPA), Movimento de Mulheres Camponesas (MMC) e o Movimento dos Trabalhadores Rurais Sem Terra (MST).

De parte do governo, houve um esforço de diálogo e negociação com a Frente Nacional de Prefeitos (FNP) e com as organizações que representam os Secretários Estaduais e Municipais de Educação, visando obter apoio ao PL. O estudo desenvolvido por Grisa, Kato e Zimmerman (2017) apontou que, em relação ao PL, os gestores das capitais e de alguns municípios de grande porte se colocavam contrários ao artigo que tornava obrigatória a aquisição de alimentos da agricultura familiar por considerarem que seria de difícil execução.

A negociação efetuada pelo governo se desdobrou em algumas alterações na versão original do PL, por ocasião da edição da Medida Provisória n ${ }^{\circ}$ 455/2008, com a exclusão do artigo que vedava explicitamente a terceirização da gestão do PNAE e a inclusão de algumas situações em que a compra da agricultura familiar poderia ser dispensada.

A edição de uma Medida Provisória foi uma estratégia adotada pelo governo federal frente aos entraves à tramitação do PL na Comissão de Constituição e Justiça (CCJ) do Senado, uma vez que o Relator apresentou parecer contrário aos dispositivos que tratavam da compra da agricultura familiar e da terceirização. A edição da MP foi marcada pelo tensionamento na interlocução entre o governo, especialmente a coordenação do PNAE e do MDA, e a comissão de mobilização e o CONSEA, uma vez que os mesmos não participaram do processo de negociação. Tanto na Câmara quanto no Congresso, a tramitação da MP transcorreu sem maiores dificuldades. Em junho de 2009 a Lei 11.947 foi sancionada pelo Presidente da República.

Em função do aprendizado institucional, os atores sociais se mobilizaram para incidir sobre a sua regulamentação, especialmente no que concernia à definição dos mecanismos de compra da agricultura familiar. Portanto houve um esforço em reorientar as diretrizes do PNAE, bem como incidir sobre a sua instrumentação, ou seja, sobre o processo de escolha dos instrumentos.

Nessa direção, ao analisar o PNAE pelo ângulo da Instrumentação da Ação Pública (IAP), proposta por Lascoumes e Le Galés $(2007$; 2014), buscamos compreender quais foram as dinâmicas, os atores e os processos políticos que resultaram na criação e adoção, pelo programa, de mecanismos voltados especificamente para a aquisição de gêneros oriundos da agricultura familiar. Tais autores questionam a visão tradicional de que os instrumentos são meros dispositivos neutros e pautados em escolhas exclusivamente 'técnicas e científicas', ao considerar que os mesmos são portadores de valores que expressam a visão de mundo dos atores, ao mesmo tempo em que atuam como tipos particulares de instituições que produzem efeitos específicos, reorganizam relações de poder, processos e fluxos de ação. 
De fato, a análise da instrumentação do PNAE mostrou que este se constituiu em um rico processo de articulação, negociação e disputa que envolveu um amplo leque de atores sociais (governamentais e não governamentais), e foi capaz de produzir inovações sociais tanto nas dinâmicas de interação entre Estado e sociedade - à medida que foram constituídos ou fortalecidos alguns espaços de participação social -, quanto nos dispositivos de compras públicas.

A regulamentação do artigo $14^{\circ}$ da Lei do PNAE dividiu-se em duas etapas. A primeira ocorreu simultaneamente à tramitação da MP no Congresso Nacional, quando foi criado informalmente um grupo de trabalho (GT Agricultura Familiar), formado, basicamente, pelos mesmos atores que participaram do processo de formulação e/ou aprovação da lei ${ }^{8}$. Tão logo a Lei 11.947 foi sancionada, a Resolução que a regulamentava foi publicada pelo FNDE (Resolução CD/FNDE no 38/2009). Havia uma enorme preocupação tanto por parte do governo quanto da sociedade civil com a imediata regulamentação do artigo $14^{\circ}$. A segunda etapa tem início em 2010, quando foi instituído formalmente pelo FNDE o Grupo Consultivo (GC PNAE), após intensa pressão das organizações que compuseram o GT AF. Essa demanda também contou com o apoio dos setores de governo que participaram da regulamentação da Lei. Todavia, este foi um longo processo de negociação, pois não havia consenso em relação a essa questão na equipe do CGPAE, tampouco no FNDE.

Alguns membros do GT AF destacaram nas entrevistas o quanto o processo de construção da normativa de compra foi desafiador e ao mesmo tempo bastante enriquecedor, pois foi escrito "a muitas mãos e mentes que pertenciam a mundos muito diferentes". Houve um momento inicial de muitos estranhamentos, uma vez que cada um tentava vocalizar suas demandas que, muitas vezes, representavam interesses distintos e até opostos, em algumas circunstâncias. As entrevistas também sinalizaram que, inicialmente, a CGPAE demonstrou dificuldades em lidar com as controvérsias produzidas nesse espaço, mas que, ao longo do processo, foi se tornando mais permeável ao diálogo e disposta a negociar, especialmente com as propostas apresentadas pela sociedade civil.

De forma geral, as entrevistas com alguns representantes dos movimentos sociais e das redes e organizações que participaram do GT indicaram que os mesmos avaliaram o processo de forma bastante positiva, ainda que inicialmente tenham ocorrido conflitos com alguns setores de governo. Nas questões mais polêmicas, as redes e movimentos tentavam se articular previamente para chegar à reunião do GT com uma proposta minimamente acordada. No que concerne aos órgãos de governo, a percepção dos entrevistados é de que existiam muitas tensões e disputas, especialmente entre os

\footnotetext{
${ }^{8}$ Gestores e técnicos de diferentes órgãos de governo (FNDE, MDA, MDS, CONAB e Ministério da Aquicultura e Pesca), organizações de representação dos gestores estaduais e municipais de educação e doze organizações da sociedade civil, dentre redes, articulações e movimentos sociais.
} 
representantes da $\mathrm{CONAB}$ e do MDA que propunham diferentes caminhos para a operacionalização da compra.

O fato de muitos integrantes, tanto do governo quanto da sociedade civil, participarem conjuntamente de outros espaços de articulação política como CONSEA, a Comissão de Mobilização pela aprovação do PL PNAE e o Grupo Gestor e Comitê Consultivo do PAA, foi apontado como um elemento que favoreceu a construção progressiva de laços de confiança e o estabelecimento de uma dinâmica de tratamento das controvérsias. A experiência prévia com o PAA também foi considerada importante, pois possibilitou que o GT partisse de uma referência comum e conseguisse tratar de forma detalhada das questões operacionais. Como resultado desses diversos conflitos e alinhamentos, foi finalmente regulamentada a compra da agricultura familiar, tendo como principal desdobramento uma elevação paulatina do percentual de recursos destinados pelo FNDE à implementação do PNAE, investidos na aquisição de produtos comercializados por agricultores familiares e suas organizações: esse percentual evoluiu de 4,9\%, em 2010, para 24,84\%, em $2016^{9}$.

\section{QUAIS OS RUMOS DA COMPRA DA AGRICULTURA FAMILIAR DO PNAE EM UM CONTEXTO DE RETROCESSOS?}

Com o processo de impeachment da então presidenta Dilma Roussef (PT), que culminou com o seu afastamento definitivo em agosto de 2016, as forças políticas que assumiram a Presidência da República deram início a um intenso processo de desmonte das políticas sociais e de desconstrução de direitos básicos de cidadania, com graves retrocessos nos espaços e dinâmicas de interação entre Estado e sociedade.

De acordo com o documento de monitoramento elaborado pela FIAN Brasil, intitulado $D a$ democratização ao Golpe: avanços e retrocessos na garantia do Direito Humano à Alimentação e à Nutrição adequadas ao Brasil, a agenda de desmonte implementada nesse período comprometia o processo de estruturação do Sistema Nacional de Segurança Alimentar e Nutricional (SISAN), e ameaçava gravemente a capacidade do Estado Brasileiro em garantir proteção social, combater a fome e promover sistemas sustentáveis de produção e consumo de alimentos nutricionalmente adequados (Santarelli et al, 2017).

A promulgação da Emenda Constitucional 95 (EC 95), em dezembro de 2016, impôs limites muito claros às políticas sociais, representando "uma ruptura com processos de pactuação voltados para a ampliação da cobertura e a melhoria da qualidade não apenas de proteção social e SAN, mas também de saúde, educação e fortalecimento da agricultura familiar, cultura, entre outros" (Santarelli et al, 2017, p.17).

\footnotetext{
${ }^{9}$ Fonte: FNDE. Ver: CONSEA. E.M. no 002-2017/CONSEA. Disponível em: http://www4.planalto.gov.br/ consea /eventos /plenarias/exposicoes-de-motivos/2017/e-m-no-002-2017. Acesso em: 15/06/2018.
} 
Em 2018, último ano do governo interino de Michel Temer (Movimento Democrático Brasileiro), a Lei Orçamentária Anual (LOA) apresentou cortes drásticos em diversas políticas e programas estratégicos para a SAN e para a agricultura familiar. De acordo com a Exposição de Motivos encaminhada pelo CONSEA à Presidência da República, a LOA 2018 destinou ao PAA apenas R\$ 750 mil reais, ou seja, um corte de 98\% em relação ao exercício anterior (2017), que já apresentava um orçamento reduzido e cujo contingenciamento alcançou $52 \%$. No que concerne à Política Nacional de Assistência Técnica e Extensão Rural (PNATER), o orçamento foi reduzido de R\$ 257 milhões para R\$34,2 milhões (Consea, 2017).

Nessa conjuntura, o CONSEA, mesmo institucionalmente fragilizado, manteve-se ativo no monitoramento do SISAN e da Política Nacional de SAN. Em março de 2018, o conselho conseguiu

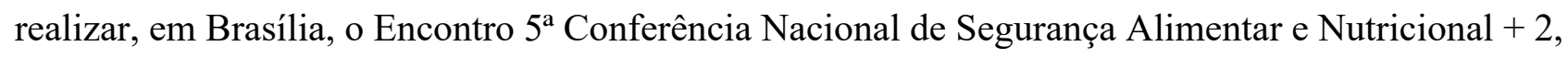
visando, dentre outros objetivos, analisar a conjuntura e seus reflexos sobre a SAN e mobilizar a sociedade civil em torno da defesa do Direito Humano à Alimentação Adequada (DHAA) e da Soberania Alimentar. A Carta Política do Encontro abordou as principais conquistas e avanços que possibilitaram que o Brasil saísse do Mapa da Fome, em 2014, ao mesmo tempo em que denunciou de forma contundente os retrocessos que estavam em curso naquele momento.

\begin{abstract}
Contudo, a atual conjuntura de retrocessos na democracia nos impôs um cenário de desconstrução de direitos, precarização das relações de trabalho, aumento do desemprego, esvaziamento de políticas públicas e iminente volta do Brasil ao Mapa da Fome. A agenda de reformas representa uma grave violação aos direitos de cidadania. Setores da sociedade brasileira, sobretudo aqueles em situação de maior vulnerabilidade, já sofrem as consequências do desmonte do sistema de proteção social devido, principalmente, à limitação dos gastos imposta pela Emenda Constitucional no 95/20164. Essas medidas compõem um modelo de Estado que atende a interesses privados e é pautado no racismo institucional, mercantilização e privatização de serviços e dos recursos naturais (pré-sal, água, energia, terras e sementes). Identificamos uma profunda incoerência entre a imposição de medidas de austeridade para a maioria da população e, por exemplo, o perdão de dívidas, subsídios e isenção fiscal para uma minoria privilegiada (Consea, 2018).
\end{abstract}

Com a eleição de Jair Bolsonaro (Partido Social Liberal) para a Presidência da República, em 2018, intensifica-se velozmente o processo de deterioração dos espaços democráticos participativos e de desmonte do SISAN. Logo em seu primeiro dia de governo, o CONSEA foi extinto por meio da Medida Provisória (MP) 870/19. Ainda que, nessa conjuntura política, a coalizão de SAN tenha se fragilizado, especialmente no que concerne à sua capacidade de incidência sobre a agenda governamental e acesso a recursos, a mesma tem se mantido ativa e articulada, tendo conseguido mobilizar uma rede ampliada de atores sociais na defesa do CONSEA, como por exemplo, personalidades da cultura brasileira, políticos, pesquisadores e cientistas, redes e associações de saúde, educação e assistência social, além de organizações internacionais.

Após intensa pressão social, o texto final da MP, aprovado pelo Congresso, restabeleceu o CONSEA no inciso XVI do artigo 24, incorporando-o à estrutura básica do Ministério da Cidadania. 
Todavia, o Presidente da República, ao sancionar a Lei $\mathrm{n}^{\circ}$ 13.844/2019, vetou o inciso que recriava o conselho. Ao ser apreciado pelo Congresso, o veto presidencial foi mantido.

Em abril de 2019, os espaços de participação social sofreram um novo ataque com a publicação do Decreto n. ${ }^{\circ}$ 9.759, que extinguiu diversos conselhos e comitês que integravam a Política Nacional de Participação Social, dentre eles o Grupo Consultivo do PNAE. Entretanto, em função de uma Ação Direta de Inconstitucionalidade (ADI 6121) que está em tramitação no Supremo Tribunal Federal (STF), a eficácia dessa medida está suspensa até o seu exame definitivo. Embora, na prática, tais espaços não estejam em funcionamento.

Uma vez que a participação social se configura em um dos pilares do SISAN, a extinção do CONSEA e demais espaços de participação social, como o Grupo Consultivo do PNAE e o Comitê Consultivo do PAA, promove uma desestruturação desse sistema, comprometendo o processo participativo de implementação da PNSAN e de programas e ações estratégicos, como o PNAE ${ }^{10}$.

No que concerne à agricultura familiar, o processo de desmonte institucional tem sido ainda mais intenso, sinalizando, em médio prazo, para a extinção das políticas públicas diferenciadas para este segmento (Sabourin, 2018). Com a reforma ministerial, a Secretaria Especial de Agricultura e Desenvolvimento Agrário (SEAD), que havia sido criada pelo governo Temer em substituição ao Ministério do Desenvolvimento Agrário, é extinta. Além disso, pela primeira vez, desde 2003, o governo federal não lançou o Plano Safra da Agricultura Familiar. Sob coordenação do Ministério da Agricultura, Pecuária e Abastecimento (MAPA), o Plano Safra 2018/2019 passou a ser destinado a “pequenos, médios e grandes produtores rurais" (Brasil, 2019).

Especialmente em relação ao PNAE, até o presente momento, não foram observadas mudanças significativas em sua institucionalidade, uma vez que não houve alteração em seu arcabouço legal, nem corte orçamentário, tendo sido mantida grande parte da equipe responsável pela gestão federal do programa. Em um cenário marcado pelo acelerado desmonte das políticas relacionadas à SAN e à agricultura familiar, a manutenção dos marcos regulatórios do PNAE sinaliza que houve um processo de institucionalização dos mecanismos de compra, que podem estar produzindo um efeito de inércia (Lascoumes; Le Galés, 2012). Outros aspectos a serem considerados referem-se à enorme capilaridade do programa e ao apoio obtido junto a uma rede ampla de atores no nível local.

\footnotetext{
${ }^{10}$ Com base nessa argumentação, a Procuradoria Federal dos Direitos do Cidadão (PFDC) encaminhou à Procuradora Geral da República, Raquel Dodge, uma representação na qual solicita que seja enviado ao STF um pedido de análise da inconstitucionalidade dos dispositivos que extinguem o CONSEA. Fonte: EXTINÇÃO do Consea desorganiza sistema que possibilitou ao Brasil sair do Mapa Mundial da Fome, alerta PFDC. Site do Ministério Público Federal. Brasília: 25 abr. 2019. Disponível em: <http://www.mpf.mp.br/pgr/noticias-pgr/extincao-do-consea-desorganiza-sistema-quepossibilitou-ao-brasil-sair-do-mapa-mundial-da-fome-alerta-pfdc $>$. Acesso em: 10 set. 2019
} 
Por outro lado, a série histórica referente à aquisição da agricultura familiar pelo PNAE aponta que, pela primeira vez desde a implementação da Lei, houve uma queda no percentual de compra que passou de 25,10\%, em 2016, para 21,49\%, em 2017 ${ }^{11}$. Os dados referentes ao ano de 2018 ainda não foram disponibilizados pelo FNDE, não sendo possível, ainda, identificar se essa tendência de recuo irá se confirmar.

\section{CONSIDERAÇÕES FINAIS}

Neste estudo, ficou evidenciado que as mudanças institucionais ocorridas no PNAE durante o período (2003-2016), que compreende os governos de coalizão liderados pelo PT, tiveram como pano de fundo um contexto marcado pela maior permeabilidade do Estado à participação social e às ideias defendidas por coalizões de atores articulados em torno da defesa da SAN e do fortalecimento da agricultura familiar, ainda que esse processo tenha sido marcado por tensões. Caracterizou-se também pela progressiva institucionalização da SAN e de políticas públicas destinadas à agricultura familiar.

Essas coalizões de atores, em função do aprendizado institucional, se articularam não só em torno da reorientação das diretrizes do PNAE, mas também buscaram incidir sobre a sua instrumentação. Cabe destacar a maior permeabilidade dos órgãos governamentais responsáveis pela regulamentação do artigo $14^{\circ}$ da Lei $11.947 / 2009$ - referente à compra da agricultura familiar - a uma dinâmica de participação social mais ativa neste tipo de atividade (de construção dos instrumentos das políticas), tradicionalmente considerada como uma tarefa administrativa e orientada por decisões meramente técnicas.

Em relação ao atual contexto, como discutido na seção 3, as condições que favoreceram as inovações sociais produzidas no âmbito do programa não se mantiveram, o que poderá comprometer, em médio prazo, o processo de compra da agricultura familiar. Primeiro, porque os espaços que possibilitavam uma participação social mais ativa no monitoramento e instrumentação da compra da agricultura familiar pelo PNAE, como o CONSEA e o Grupo Consultivo, foram extintos. O desmantelamento da Política Nacional de Participação Social e a desestruturação do SISAN também compromete, sobremaneira, a capacidade de incidência políticas das coalizões de causa que estiveram diretamente envolvidas com a aprovação da Lei do PNAE e sua instrumentação.

Em segundo, porque a fragilização da institucionalidade da agricultura familiar enfraquece ainda mais a capacidade desse segmento em atender ao mercado institucional da alimentação escolar. A compra da agricultura familiar pelo PNAE está conectada com outros instrumentos da ação pública, operacionalizados pela área da educação, mas também por outros setores de governo como a

11 FNDE. PNAE. Dados da Agricultura Familiar. Brasília: 2018. Disponível em: $<$ http://www.fnde.gov.br/index.php/programas/pnae/pnae-consultas/pnae-dados-da-agricultura-familiar $>$. Acesso em: 10 set. 2019. 
vigilância sanitária, a alimentação e nutrição, o desenvolvimento agrário e o abastecimento, conformando-se assim, uma verdadeira teia de instrumentos.

Além disso, é possível que o cenário de criminalização das organizações sociais e das lutas dos movimentos do campo afete a vontade dos agricultores familiares em ter um vínculo institucional e de mercado com o poder público, o que merece ser aprofundado em outros estudos. E, a exemplo do que ocorreu em outros momentos da história do programa, as possíveis descontinuidades, em um cenário futuro, podem inibir o aprofundamento ou mesmo a continuidade desse processo de inovação social. Assim, é de extrema relevância a realização de novos estudos que monitorem e analisem os rumos a serem tomados pelo programa no atual contexto político.

\section{REFERÊNCIAS}

BRASIL. Lei $n^{\circ} 11.947$, de 16 de junho de 2009. Dispõe sobre o atendimento da alimentação escolar e do Programa Dinheiro Direto na Escola aos alunos da educação básica. Disponível em: $<$ http://www.planalto.gov.br/ccivil_03/_ato2007-2010/2009/lei/111947.htm>. Acesso em: 10 jun. 2018.

BRASIL. Lei $n^{\circ}$ 8.666, de 21 de junho de 1993a. Regulamenta o art. 37, inciso XXI, da Constituição Federal, institui normas para licitações e contratos da Administração Pública e dá outras providências. Disponível em: <http://www.planalto.gov.br/ccivil_03/Leis/18666cons.htm>. Acesso em: 15 jun. 2018.

BRASIL. Lei $n^{\circ} 13.844$, de 18 de junho de 2019. Estabelece a organização básica dos órgãos da Presidência da República e dos Ministérios; altera as Leis nos 13.334, de 13 de setembro de 2016, 9.069, de 29 de junho de 1995, 11.457, de 16 de março de 2007, 9.984, de 17 de julho de 2000, 9.433, de 8 de janeiro de 1997, 8.001, de 13 de março de 1990, 11.952, de 25 de junho de 2009, 10.559, de 13 de novembro de 2002, 11.440, de 29 de dezembro de 2006, 9.613, de 3 de março de 1998, 11.473, de 10 de maio de 2007, e 13.346, de 10 de outubro de 2016; e revoga dispositivos das Leis no 10.233, de 5 de junho de 2001, e 11.284, de 2 de março de 2006, e a Lei ${ }^{\circ} 13.502$, de $1^{\circ}$ de novembro de 2017. Disponível em: <http://www.planalto.gov.br/ccivil_03/_ato20192022/2019/Lei/L13844.htm>. Acesso em: 09 set. 2019.

BRASIL. Ministério da Agricultura, Pecuária e Abastecimento. Plano Safra. Brasília: 2019. Disponível em: <http://www.agricultura.gov.br/plano-safra>. Acesso em: 9 set. 2019.

BRASIL. Presidência da República. Decreto n. ${ }^{\circ}$ 9.759, de 11 de abril de 2019.

Extingue e estabelece diretrizes, regras e limitações para colegiados da administração pública federal. Disponível em: < http://www.planalto.gov.br/ccivil_03/_ato2019-2022/2019/decreto/D9759.htm>. Acesso em: 09 set. 2019.

BRASIL. Presidência da República. Medida Provisória nº70, de 1 de janeiro de 2019. Estabelece a organização básica dos órgãos da Presidência da República e dos Ministérios. Disponível em: < http://www.planalto.gov.br/ccivil_03/_Ato2019-2022/2019/Mpv/mpv870.htm>. Acesso em: 09 set. 2019.

BRASIL. TCU - Tribunal de Contas da União. Auditoria Operacional nos Programas de Suplementação Alimentar do Governo Federal: Programa Nacional de Alimentação Escolar PNAE/FAE; Programa de Suplementação Alimentar - PSA/INAN; Programa de Apoio Nutricional PAN/LBA; Programa de Alimentação do Trabalhador - PAT/MTb. Processo nº TC 001.317/93-8. 
Brasília:

1993b,

$259 \mathrm{p}$.

Disponível

em:

$<$ http://www.tcu.gov.br/Consultas/Juris/Docs/judoc/Dec/19940907/GERADO_TC-17897.pdf>.

Acesso em: 09 set. 2019.

CARVALHO, D. G. O Programa Nacional de Alimentação Escolar e a sustentabilidade: o caso do Distrito Federal. Brasília, 2009. 238f. Dissertação (Mestrado em Desenvolvimento Sustentável) Centro de Desenvolvimento Sustentável, UnB, 2009.

COIMBRA, M. Alimentação Escolar no Brasil: Política e Instituição. Relatório Técnico. Brasília, 1981.

CONSEA. Carta final da $5^{a}$ Conferência Nacional de Segurança Alimentar e Nutricional +21.

Brasília: 2018. Disponível em: <https:/contrafbrasil.org.br/system/uploads/ck/files/Carta-finalpapel-timbrado-evento(1).pdf $>$. Acesso em: 9 set. 2019.

CONSEA. Exposição de Motivos no 003-2018, de 20 de junho de 2018. Brasília: 2018.

FNDE. PNAE. Dados da Agricultura Familiar. Brasília: 2018. Disponível em: < http://www.fnde.gov.br/index.php/programas/pnae/pnae-consultas/pnae-dados-da-agriculturafamiliar>. Acesso em: 10 set. 2019.

GRISA, C. Políticas Públicas para a agricultura familiar no Brasil: produção e institucionalização das ideias. Rio de Janeiro, 2012. 280f. Tese (Doutorado em Ciências Sociais) - Instituto de Ciências Humanas e Sociais, Programa de Pós-Graduação em Desenvolvimento, Sociedade e Agricultura Universidade Federal Rural do Rio de Janeiro, 2012.

GRISA, C; KATO, K; ZIMMERMANN, S.A. O Rural nas Políticas Públicas do Brasil Contemporâneo. In: MIRANDA, C (Org). Tipologia Regionalizada dos Espaços Rurais Brasileiros:Implicações no Marco Jurídico e nas Políticas Públicas. Brasília: IICA, 2017. pp. 337462.

GRISA, C.; SCHNEIDER, S. Três Gerações de Políticas Públicas para a Agricultura Familiar e Formas de Interação entre Sociedade e Estado no Brasil. RESR, Piracicaba-SP, v. 52, Supl. 1, pp.125146, 2014.

LASCOUMES, P.; LES GALÈS, P. Sociologie de l'action publique. Paris: Armand Colin, 2012.

LEÃO, Marília; MALUF, Renato S. A construção de um sistema público de segurança alimentar e nutricional: a experiência brasileira. Brasília: ABRANDH, 2012.

MALUF, R. Compras governamentais para a alimentação escolar e a promoção da agricultura familiar. Observatório de Políticas Públicas para a Agricultura. n.27. jun. 2009.

MOULAERT, F. et al. Towards alternative models of local innovation. Urban Studies, v. 42, n. 11, p. 1969-1990, 2005.

PEIXINHO, A.M.L. Um resgate histórico do Programa Nacional de Alimentação Escolar - PNAE. São Paulo, 2011. 133f. Dissertação (Mestrado Profissional em Ensino em Ciências da Saúde) Universidade Federal de São Paulo, 2011.

PICOLOTTO, E. L. As Mãos que Alimentam a Nação: agricultura familiar, sindicalismo e política. Rio de Janeiro, 2011. 289f. Tese (Doutorado em Ciências Sociais) - Instituto de Ciências Humanas e Sociais, Programa de Pós-Graduação de Ciências Sociais em Desenvolvimento, Agricultura e Sociedade, Universidade Federal Rural do Rio de Janeiro. 2011.

SABATIER, P.A.; JENKINS-SMITH, H. Policy change and learning: an advocacy coalition framework. Boulder: Westview, 1993.

SABATIER, P.A; WEIBLE, C. M. The advocacy coalition framework: Innovations, and clarifications. In: SABATIER, P.A (Org.). Theories of the Policy Process. Boulder: Westview Press,2007, p. 189-220. 
SABOURIN, Eric. Erosão, crise e desmonte de políticas para a agricultura familiar e agroecologia na America Latina. In: Anais do Seminario "Políticas públicas para o meio rural brasileiro no período recente: mudanças, continuidades e rupturas”. Rio de Janeiro: CPDA-UFRRJ, 2018.17 p.

SCHOTTZ, V. Programa Nacional de Alimentação Escolar (PNAE): controvérsias sobre os instrumentos de compras de alimentos produzidos pela Agricultura Familiar. Rio de Janeiro, 2017. 228f. Tese (Doutorado em Ciências Sociais) - Programa de Pós-Graduação de Ciências Sociais em Desenvolvimento, Agricultura e Sociedade, Universidade Federal Rural do Rio de Janeiro, 2017.

SANTARELLI, M. et al. Da democratização ao golpe: avanços e retrocessos na garantia do direito humano à alimentação e à nutrição adequadas no Brasil. Brasília: FIAN Brasil, 2017.

TURPIN, M. E. A alimentação escolar como vetor de desenvolvimento local e garantia de segurança alimentar e nutricional. São Paulo, 2008. 176f. Dissertação (Mestrado em Desenvolvimento Econômico) - Instituto de Economia, Universidade Estadual de Campinas, 2008.

WEIBLE, C. M.; SABATIER, P. A.; McQUEEN, K. Themes and variations: taking stock of the Advocacy Coalition Framework. The Policy Study Journal, v. 37, n. 1, p.121-140, fev. 2009.

ZIMMERMANN, S.A. A pauta do povo e o povo em pauta: as Conferências Nacionais de Segurança Alimentar e Nutricional, Brasil - Democracia, participação e decisão política. Rio de Janeiro, 2011. 200f. Tese (Doutorado) - Instituto de Ciências Humanas e Sociais, Universidade Federal Rural do Rio de Janeiro. 2011. 